\title{
Strategi Public Relations Dalam Rebranding Bekasi Square Menjadi Revo Town
}

\author{
${ }^{1}$ Sumiyati, ${ }^{2}$ Euis Komalawati, ${ }^{3}$ Angelika Rosma \\ Institut Ilmu Sosial dan Manajemen STIAMI \\ Program Studi Manajemen Komunikasi - Fakultas Ilmu Sosial dan Manajemen \\ email : ${ }^{1}$ summiyati03@gmail.com, ${ }^{2}$ e_komalawati@yahoo.com, ${ }^{3}$ be_shabrina@yahoo.com
}

\section{ABSTRACT}

The main purpose of the research is to know how the Public Relations' strategy of rebranding Bekasi Square for Revo Town. This research method used qualitative descriptive approach with a study case method. The technique of collecting data through in-depth interviews, documentation, and literature studies. Based on the research results, the rebranding stages' strategy of Bekasi Square for Revo Town are carried out through four stages, namely fact-finding, planning-decision, communication-action, and evaluation. At the first stage, it is known the reason for rebranding Revo Town is the existence of fierce competition in the field of modern retail and to make repairs and rejuvenation of Revo Town. At the planning-decision stage there is a rebranding factor, namely the acquisition of Revo Town by Farpoint and the number of malls that grow and develop in Bekasi, the purpose of rebranding is to show Revo Town commitment and improve the quality. In the communication-action phase there is a rebranding process, namely repositioning where Revo Town further strengthens the Revo Town brand as a textile mall in Bekasi. Renaming Revo Town is by changing the name of Bekasi Square to Revo Town. Redesigning Revo Town includes changes to the logo that currently dominates using orange, and changes the

Keywords:

Public Relations Strategy, Rebranding
Revo Town tagline to simply a place for togetherness and family quality time. Relaunching Revo Town was held by holding a press conference and distributing press releases. The evaluation stage in Revo Town rebranding is done every six months by giving a questionnaire to the tenants and visitors of Revo Town.

\section{PENDAHULUAN}

Pertumbuhan bisnis ritel modern di Indonesia saat ini telah mengalami perkembangan. Hal ini didorong adanya perkembangan teknologi dan perubahan gaya hidup masyarakat dari waktu ke waktu. Ritel modern hadir dengan konsep one stop shopping dimana konsumen dapat memenuhi semua kebutuhan yang diperlukan dalam satu lokasi. Selain itu, ritel modern menawarkan banyak kelebihan sehingga semakin diminati oleh masyarakat. Salah satu bentuk bisnis ritel modern yang sekarang telah berkembang adalah pusat perbelanjaan atau yang sering kita sebut mal.

Mal yang telah menjadi bagian dari gaya hidup masyarakat perkotaan harus memiliki karakteristik dan konsep yang disesuaikan dengan target khalayak dari mal tersebut. Pihak manajemen mal harus mampu melihat dan menyikapi setiap perubahan yang ada, sesuai dengan tren yang berkembang di masyarakat agar masyarakat tetap mengetahui brand dan positioning dari mal tersebut. Karena banyaknya pesaing yang hadir, sebuah perusahaan memerlukan peran Public Relations guna membentuk sebuah brand image agar pusat perbelanjaan tersebut memperoleh positioning dalam benak target konsumen.

Dalam membentuk sebuah brand, Public Relations harus memiliki strategi yang dapat meyakinkan konsumen terhadap brand yang dimilikinya. Salah satu bentuk strategi yang dapat dilakukan oleh organisasi untuk menyegarkan kembali sebuah brand serta untuk memberikan kepuasan maksimal kepada konsumen yaitu dengan rebranding. Seperti yang dilakukan oleh PT. Kilap Propertindo. Pada tanggal 17 September 2015, PT. Kilap Propertindo yang berada dibawah naungan Gunung Sewu Group melakukan rebranding mal Bekasi Square menjadi Revo Town. 
Dalam dunia bisnis, sebuah organisasi melakukan rebranding produknya merupakan hal yang tidak asing lagi. Karena ketika sebuah organisasi yang telah memiliki brand dan organisasi merasa brand-nya telah usang maka penambahan atribut yang lebih segar harus segera dilakukan agar brand tersebut mendapat identitas baru dan dapat terus diingat oleh masyarakat. Rebranding dapat diartikan dari makna kata re yang berarti kembali dan branding yang merupakan proses penciptaan brand image yang menghubungkan hati dan benak konsumennya. Rebranding merupakan upaya yang dilakukan oleh perusahaan atau lembaga untuk mengubah atau memperbarui sebuah brand yang telah ada agar menjadi lebih baik dengan tidak mengabaikan tujuan awal perusahaan yaitu berorientasi profit.

Memiliki posisi merupakan syarat bagi pembentukan merek yang kuat. Dengan adanya posisi, suatu merek akan lebih mudah dikenal oleh konsumen. Dalam menciptakan brand positioning suatu perusahaan harus memiliki karakteristik yang unik disetiap produknya. Seperti Bekasi Square yang memiliki karakteristik sebagai mal tekstil di wilayah kota Bekasi, sehingga menjadikan Bekasi Square memiliki karakteristik yang berbeda dengan mal lainnya yang berada di Bekasi. Mal tekstil merupakan pusat perbelanjaan yang menyediakan tenant tekstil lebih banyak dibanding tenant lainnya yang bergabung di pusat perbelanjaan tersebut. Brand image Revo Town sebagai mal tekstil terlihat dimana hampir setengah dari tenant yang bergabung di Revo Town merupakan tenant yang menyediakan bahan tekstil.

Beberapa kajian yang relevan dengan penelitian ini antara lain Penelitian terdahulu yang pertama dilakukan oleh Prasetya Yoga Santoso, Rialdo Rezeky M. L. Toruan, dalam Jurnal Pustaka Komunikasi Vol 1, No 1 (2018) dengan judul "Strategi Marketing Public Relations dalam Rebranding HSBC Indonesia untuk membentuk Brand Awareness". Penelitian ini menjelaskan strategi marketing Public Relations dalam rebranding HSBC Indonesia untuk membentuk brand awareness. Hasil penelitian yang diperoleh yaitu perubahan yang dilakukan manajemen HSBC menjadi HSBC Indonesia adalah dengan integrasi bersama Bank Ekonomi. Proses rebranding tersebut dengan memanfaatkan media massa untuk menyiarkan berbagai pemberitaan HSBC Indonesia. Dengan special events yaitu roadshow 5 kota besar Jakarta, Medan, Surabaya, Bandung dan Makassar.

Penelitian kedua dilakukan oleh Natasha Helena Kairupan, Susanne Dida, Heru Ryanto Budiana dalam Jurnal Educational Technology (EDUTECH) Vol 15, No 3 (2016) dengan judul "Corporate Rebranding of Gramedia Store (Corporare Rebranding di Gramedia Store). Penelitian ini memaparkan tahapan analisis dilakukan dengan menganalisis pasar melalui insights dan foresights, audit merek dengan analisis SWOT, dan mengidentifikasi peluang.

Selanjutnya penelitian ketiga dilakukan oleh Laily Maknin Zubaedah dalam Jurnal Ilmiah Teknik dan Manajemen Industri (JITMI) Vol 1, No 1 (2018) dengan judul "Corporate Rebranding Tokobagus.com menjadi OLX.co.id". Berdasarkan hasil penelitian, dalam mengenalkan atau menginformasikan kepada masyarakat mengenai corporate rebranding yang dilakukan oleh tokobagus.com menjadi OLX.co.id digunakan promotional tools. Dari hasil analisis yang diperoleh yaitu salah satu promotional tools yang banyak digunakan dalam mengenalkan dan menginformasikan rebranding yang dilakukan yaitu melalui internet.

Berdasarkan uraian diatas, maka penulis tertarik untuk menganalisis "Strategi Public Relations dalam Rebranding Bekasi Square menjadi Revo Town". Penelitian ini bertujuan menganalisis strategi Public Relations yang digunakan dalam proses rebranding Bekasi Square menjadi Revo Town. Peneliti mengkombinasikan program kerja humas Cutlip \& Center (1982) dalam buku Ruslan (2014:148-149) yang terdiri dari empat tahap yaitu fact finding, planningdecisions, communication-action, evaluation dengan model proses rebranding Muzellec \& Lambkin (2006) yang terdiri dari empat tahap yaitu repositioning, renaming, redesigning, dan relaunching. 


\section{KERANGKA TEORITIS \\ 2.1 Public Relations}

Public Relations menurut Jefkins (2003:10) adalah bentuk komunikasi yang terencana, baik kedalam maupun keluar, antara organisasi dan semua khalayaknya dalam rangka mencapai tujuantujuan spesifik yang berlandasakan saling pengertian. Public Relations dalam konteks branding yaitu pihak yang berfungsi sebagai jembatan untuk menyampaikan aktifitas branding perusahaan kepada publik eksternal demi tujuan yang ingin dicapai.

Aktifitas Public Relations tidak hanya terfokus pada ruang lingkup publik internal dan eksternal, akan tetapi dalam organisasi Public Relations dapat mendukung program pemasaran. Organisasi membutuhkan peran Public Relations untuk membentuk brand image agar produk yang dipasarkan dapat dikenal oleh konsumen. Dalam pemasaran produk, Public Relations dapat berkontribusi dalam berbagai kegiatan seperti membangun citra perusahaan yang dapat menguntungkan penjualan produk, membantu peluncuran produk terbaru perusahaan serta membantu reposisi sebuah produk.

\subsection{Strategi Public Relations}

Strategi pada dasarnya bertujuan untuk mencapai sebuah tujuan yang telah di rencanakan oleh suatu organisasi. Strategi yang disusun dalam sebuah organisasi berhubungan dengan kepuasan konsumennya. Menurut Adnanputra, arti strategi adalah bagian terpadu dari suatu rencana (plan), sedangkan rencana merupakan produk dari suatu perencanaan (planning), yang pada akhirnya perencanaan adalah salah satu fungsi dari proses manajemen. (Ruslan, 2014:133). Adnanputra menjelaskan pengertian Strategi Public Relations, yaitu "alternative optional yang dipilih untuk ditempuh guna mencapai tujuan Public Relations dalam kerangka suatu rencana Public Relations (Public Relations Plan).” (Ruslan, 2014:134).

Dari pengertian diatas, dapat diambil kesimpulan bahwa strategi Public Relations merupakan suatu tahapan perencanaan dari seorang Public Relations dalam menjalankan tahaptahap yang telah ditetapkan demi mencapai tujuan organisasi. Dalam melaksanakan program kerja kehumasan menurut Cutlip \& Center (1982) dalam buku Ruslan (2014:148-149), terdapat empat tahapan atau langkah-langkah pokok yang menjadi acuan yaitu: penelitian dan mendengarkan (research-listening), perencanaan dan pengambilan keputusan (Planning-decision), mengkomunikasikan dan pelaksanaan (communication-action), serta mengevaluasi (evaluasi).

\subsection{Brand}

Brand merupakan suatu tanda yang dijadikan pengenal bagi sebuah produk. Kotler dan Armstrong (2012) menyatakan Merek adalah sebuah nama, istilah, tanda, simbol, atau desain atau sebuah kombinasi diantaranya yang bertujuan untuk mengidentifikasi konsumen dalam berbagai cara. Nama merek membantu konsumen untuk mengidentifikasi produk yang mungkin memberikan manfaat bagi konsumen. Merek juga menyatakan sesuatu tentang konsistensi dan kualitas (Priansa, 2017:242). Manfaat brand bagi konsumen menurut Temporal dan Lee (2002) yaitu brand dapat memberikan pilihan, memudahkan pengambilan keputusan, memberikan jaminan kualitas dan memberikan pencegahan resiko.

\subsection{Rebranding}

Rebranding diartikan dari makna kata re yang berarti kembali dan branding yang merupakan suatu proses penciptaan brand image yang menghubungkan hati dan benak pelanggannya. Rebranding adalah upaya yang dilakukan oleh perusahaan atau lembaga untuk mengubah atau memperbarui sebuah brand yang telah ada agar menjadi lebih baik dengan tidak 
mengabaikan tujuan awal perusahaan yaitu berorientasi profit. Muzellec menyatakan bahwa rebranding adalah menciptakan suatu nama yang baru, istilah, simbol, desain atau kombinasi semuanya untuk brand yang tidak dapat dimungkiri dengan tujuan mengembangkan diferensiasi posisi didalam pikiran dari stakeholder dan pesaing. (Priansa, 2017:268)

Menurut Muzellec \& Lambkin (2006) beberapa faktor penyebab terjadinya perubahan merek atau yang disebut dengan rebranding, yaitu perubahan kepemilikan (merger, akuisisi, perusahaan yang go public), perubahan strategi korporat (diversifaksi, divestasi, internasionalisasi dan lokalisasi), perubahan pada posisi persaingan (citra yang menurun, penggerusan pangsa pasar, dan masalah reputasi), serta perubahan lingkungan eksternal.

Ada empat proses rebranding menurut Muzellec., et al (2003), yaitu pertama, perubahan posisi brand dibenak konsumen (repositioning). Proses ini dianggap lebih dinamis karena merupakan proses tambahan dimana harus selalu diatur setiap waktu untuk selalu siap dengan perubahan market trend dan tekanan kompetitif dalam eksternal event yang lebih luas. Brand positioning bertujuan untuk menempatkan posisi merek yang baru secara radikal dibenak konsumen, pesaing dan stakeholdernya.

Kedua, perubahan nama (renaming) merupakan yang paling komprehensif dan paling beresiko dalam proses rebranding. Renaming menjadi tahapan dimana nama baru menjadi media mengirimkan sinyal kuat kepada seluruh stakeholder bahwa perusahaan atau brand melakukan perubahan strategi, perubahan fokus, atau perubahan struktur kepemilikan. Ketiga, perubahan design (redesigning) adalah mendesain ulang logo, gaya, dan pesan seiring dengan menciptakan merek baru. Nama, slogan, dan logo merupakan elemen penting dalam merancang sebuah merek, karena merupakan kebutuhan perusahaan untuk membangun misi dan nilai-nilai dalam proses rebranding.

Keempat, pengkomunikasian brand baru (relaunching) adalah peluncuran atau pemberitahuan brand baru ke dalam internal dan eksternal perusahaan. Untuk internal perusahaan dapat dilakukan melalui brosur, bulletin, internal meeting danjuga melalui workshop atau internet. Sedangkan untuk eksternal perusahaan dapat melalui press release, advertising, dan media lainnya untuk menarik perhatian akan brand baru tersebut dan juga dapat memfasilitasi proses adopsi dari nama baru tersebut kepada stakeholder.

Dibawah ini terdapat bagan yang menjabarkan proses rebranding menurut Muzellec \& Lambkin (2006) yang dibentuk dalam suatu model. Model rebranding dibawah ini terdiri dari faktor-faktor penyebab rebranding, tujuan rebranding, dan proses rebranding.

Gambar 1. Model Process Rebranding

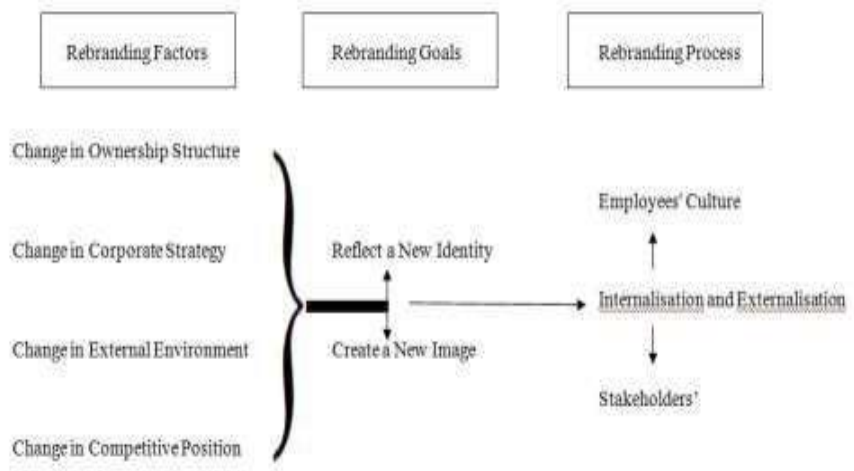

Sumber: Goi\&Goi, Review Models and Reasons of Rebanding (2011:446)

Dari bagan diatas menunjukkan bahwa rebranding dilakukan karena adanya faktor-faktor rebranding seperti perubahan struktur kepemilikan perusahaan, perubahan strategi perusahaan, perubahan pada lingkungan eksternal perusahaan dan perubahan posisi kompetitif. Keempat faktor 
tersebut menjadi landasan untuk membentuk citra baru yang mencerminkan identitas baru perusahaan sebagai tujuan dilakukannya rebranding. Dalam mencapai tujuan rebranding tersebut tentunya akan melalui suatu proses, oleh karena itu strategi rebranding ini dibentuk dari hasil kerja pihak internal perusahaan (karyawan) dan kerjasama serta adanya feedback pihak eksternal perusahaan yaitu konsumen dan pelanggan.

\subsection{Positioning}

Positioning adalah kegiatan dalam mendesain citra dan penawaran perusahaan untuk menempati tempat yang khas dalam benak pangsa pasar. Maknanya, positioning tersebut mencari 'posisi' di dalam pasar, pencarian posisi dilakukan setelah menentukan strategi segmentasi yang dipakai. Positioning adalah usaha suatu organisasi untuk membentuk suatu brand atau merek yang dimilikinya untuk berada di dalam benak konsumen. Jadi suatu brand atau merek sangat penting dalam positioning karena brand atau merek tersebut sebagai alat untuk memposisikan produk dari suatu organisasi dalam benak konsumen.

\section{METODE PENELITIAN}

Jenis pendekatan yang digunakan dalam penelitian ini adalah pendekatan deskriptif kualitatif dengan metode studi kasus. Penelitian kualitatif adalah suatu penelitian ilmiah, yang bertujuan untuk memahami suatu fenomena dalam konteks sosial secara alamiah dengan mengedepankan proses interaksi komunikasi yang mendalam antara peneliti dengan fenomena yang diteliti (Herdiansyah, 2010:9). Inti studi kasus yaitu kecenderungan utama studi ini berusaha untuk menyoroti suatu keputusan atau seperangkat keputusan : mengapa keputusan itu diambil, bagaimana diterapkan dan apakah hasilnya (Schramm dalam Yin, 1981). Jenis studi kasus yang digunakan adalah single case single analysis yakni studi kasus yang menyoroti perilaku individu atau kelompok dengan satu masalah penting, dalam penelitian ini studi kasus bagian PR Revo Town yang menyoroti masalah strategi PR.

Untuk mendapatkan data yang lengkap dan akurat serta dapat dipertanggungjawabkan kebenaran ilmiahnya, maka peneliti menggunakan teknik pengumpulan data melalui wawancara mendalam, dokumentasi serta studi kepustakaan. Kriteria yang akan menjadi informan dalam penelitian ini yaitu pihak perusahaan yang menangani proses rebranding Bekasi Square menjadi Revo Town. Informan dalam penelitian ini yaitu manajer marketing communication Revo Town, staf marketing communicaton Revo Town, pengunjung loyal Revo Town serta akademisi komunikasi.

\section{HASIL PENELITIAN DAN DISKUSI}

Berdasarkan hasil wawancara dengan narasumber maka didapatkan hasil penelitian bahwa strategi Public Relations dalam rebranding Bekasi Square menjadi Revo Town dilakukan dalam beberapa tahap, yaitu tahap fact finding, tahap planning-decisions, tahap communication-action, dan tahap evaluation.

\section{a. Tahap fact finding.}

Pada tahap fact finding, diketahui alasan Bekasi Square melakukan rebranding menjadi Revo Town yaitu adanya persaingan pusat perbelanjaan yang semakin ketat di kota Bekasi serta untuk melakukan perbaikan dan peremajaan Revo Town supaya tetap dikenal masyarakat.

\section{b. Tahap planning-decisions}

Selanjutnya tahap planning-decisions terdiri dari tiga tahap, yaitu (1) faktor rebranding Revo Town, melalui faktor internal karena adanya akuisisi dari PT. Kilap Propertindo kepada Farpoint, dan faktor eksternal karena adanya persaingan dengan banyaknya mal baru yang tumbuh

Sumiyati, Euis Komalawati, Angelika Rosma (Strategi Public Relation dalam Rebranding...) 
dan berkembang di kota Bekasi; (2) Tujuan rebranding : Pertama, untuk menunjukan komitmen kepada masyarakat untuk tetap menjadi pusat perbelanjaan yang menarik untuk dikunjungi. Kedua, untuk meperbaiki kualitas dengan cara melakukan perubahan secara façade gedung, tenancy mix dan zoning lebih menarik. (3) Proses rebranding meliputi repositioning, renaming, redesigning, serta relaunching.

\section{c. Tahap Communication-Action}

Tahap Communication-Action dilakukan melalui repositioning, renaming, redesigning, dan relaunching. Pertama, tahap repositioning Revo Town dilakukan dengan cara memperkuat brand Revo Town yang merupakan satu-satunya pusat perbelanjaan dengan tenant tekstile terlengkap dan terbesar di kota Bekasi. repositioning yang dilakukan Revo Town dengan menawarkan brand image yang berbeda dari pusat perbelanjaan lainnya merupakan suatu peluang bagi Revo Town untuk menarik pengunjung datang ke Revo Town. repositioning ini dinilai cukup efektif untuk menarik minat belanja masyarakat karena Revo Town hadir dengan segmentasi yang berbeda dari pusat perbelanjaan lainnya.

Kedua, renaming merupakan tahapan rebranding dimana perusahaan telah mengganti nama produk mereka. Semenjak tahun 2008 sampai sebelum dilakukan rebranding nama pusat perbelanjaan tersebut yaitu Bekasi Square. Setelah dilakukan rebranding pada tahun 2014 nama pusat perbelanjaan tersebut berubah menjadi Revo Town. Nama baru Revo Town berasal dari kata Revo yang merujuk dari kata "revolution" yang berarti inovasi dan transformasi sedangkan "Town" mempresentasikan sebagai tempat "a melting pot" untuk teman dan keluarga. Nama baru Revo Town ini sesuai dengan tagline Revo Town yaitu simply a place for togetherness and family quality time. Namun, tagline baru Revo Town tersebut dinilai kurang efektif karena tagline Revo Town lebih sulit untuk dilafalkan oleh masyakat dan terlalu panjang. Oleh karena itu, masyarakat banyak yang tidak mengerti makna tagline baru Revo Town tersebut. Sehingga, pesan yang ingin disampaikan melalui tagline tersebut tidak diterima dengan baik oleh masyarakat. Hal ini berbeda dengan tagline sebelum dilakukan rebranding yang menggunakan kata-kata yang lebih pendek dan mudah diingat oleh masyarakat.

Ketiga, tahap redesigning dalam proses rebranding Bekasi Square menjadi Revo Town yaitu dengan mengubah elemen tangible perusahaan seperti logo, tagline, atau elemen visual lainnya. Sebelum dilakukan rebranding, pusat perbelanjaan Bekasi Square menggunakan huruf yang penuh dengan warna yang sesuai dengan tagline Bekasi Square yaitu ceria setiap saat. Setelah dilakukan rebranding, logo Revo Town didominasi warna orange dengan permainan garis yang dinamis. Warna orange ini memberikan kesan hangat dan bersemangat. Hal ini selaras dengan tagline Revo Town yang ingin menjadikan Revo Town sebagai pusat perbelanjaan yang dapat memberikan kesan hangat dan nyaman bagi pengunjung. Garis dinamis yang dibentuk juga mencerminkan bahwa Revo Town dapat terus berkembang seiring dengan perkembangan zaman dengan terus melakukan inovasi dan transformasi. Keempat, proses relaunching Revo Town berlangsung pada 19 mei 2016 di Atrium Lantai Dasar Revo Town. Pada tahap relaunching Revo Town, divisi Marketing Communicationss yang menangani proses rebranding Bekasi Square menjadi Revo Town mengadakan press conference dengan mengundang beberapa media. Selain itu, Marketing Communicationss Revo Town membuat press release. Relaunching ini dilaksanakan bertujuan untuk menyebarkan informasi kepada masyarakat bahwa Bekasi Square telah melakukan rebranding menjadi Revo Town.

\section{d. Tahap Evaluation}

Evaluasi yang dilakukan Revo Town bertujuan untuk menegetahui apakah rebranding yang dijalankan telah berhasil atau tidak. Strategi yang digunakan Revo Town dalam melakukan evaluasi yaitu dengan membagikan quesioner kepada tenant dan pengunjung Revo Town. Evalusi ini dijalankan setiap enam bulan sekali. Indikator keberhasilan evaluasi ini yaitu masyarakat aware sama perubahan yang dilakukan oleh Revo Town serta adanya peningkatan jumlah pengunjung.

Sumiyati, Euis Komalawati, Angelika Rosma (Strategi Public Relation dalam Rebranding...) 
Dalam melaksanakan rebranding tersebut, Marketing Communication Revo Town merancang beberapa strategi agar proses rebranding tersebut dapat diterima oleh masyarakat. Strategi yang digunakan oleh Marketing Communication Revo Town dalam memperkenalkan brand baru Revo Town yaitu dengan melakukan tenant gathering, mengadakan event atau pameran serta mengadakan program loyalitas konsumen. Temuan ini mendukung penelitian Prasetya Yoga Santoso, Rialdo Rezeky M. L. Toruan yang tidak hanya menekankan penggunaan media massa namun juga pentingnya special event dalam rebranding.

Tabel 1. Strategi Revo Town

\begin{tabular}{ll}
\hline \multicolumn{1}{c}{ Tahap } & \multicolumn{1}{c}{ Keterangan } \\
\hline Fact Finding & alasan Bekasi Square melakukan rebranding menjadi Revo Town yaitu adanya \\
& persaingan pusat perbelanjaan \\
\hline Planning-decisions & Faktor rebranding Pertama, faktor internal karena adanya akuisisi dari PT. \\
& Kilap Propertindo kepada Farpoint. Kedua, faktor eksternal karena adanya \\
& persaingan dengan banyaknya mal baru yang tumbuh dan berkembang di kota \\
& Bekasi;.
\end{tabular}

Tujuan rebranding : Pertama, untuk menunjukan komitmen kepada masyarakat untuk tetap menjadi pusat perbelanjaan yang menarik untuk di kunjungi. Kedua, untuk memperbaiki kualitas dengan cara melakukan perubahan secara façade gedung, tenancy mix dan zoning lebih menarik

Proses rebranding meliputi repositioning, renaming, redesigning, serta relaunching.

\begin{tabular}{lll}
\hline $\begin{array}{l}\text { Communication- } \begin{array}{l}\text { Repositionin } \\
\text { Action }\end{array} \\
\text { Renaming }\end{array}$ & $\begin{array}{l}\text { memperkuat brand Revo Town yang merupakan satu- } \\
\text { satunya pusat perbelanjaan dengan tenant tekstile } \\
\text { terlengkap dan terbesar di kota Bekasi }\end{array}$ \\
\cline { 2 - 3 } & $\begin{array}{l}\text { Nama baru Revo Town berasal dari kata Revo yang } \\
\text { merujuk dari kata "revolution" yang berarti inovasi dan } \\
\text { transformasi sedangkan "Town" mempresentasikan sebagai } \\
\text { tempat "a melting pot" untuk teman dan keluarga. Nama } \\
\text { baru Revo Town ini sesuai dengan tagline Revo Town yaitu } \\
\text { simplya place for togetherness and family quality time. }\end{array}$ \\
\hline Redesigning & $\begin{array}{l}\text { Logo Revo Town didominasi warna orange dengan } \\
\text { permainan garis yang dinamis. Warna orange ini }\end{array}$ \\
& memberikan kesan hangat dan bersemangat. Garis dinamis \\
& yang dibentuk mencerminkan Revo Town dapat terus \\
& berkembang seiring dengan perkembangan zaman dengan \\
& terus melakukan inovasi dan transformasi. \\
\hline Relaunching & Marketing Communications mengadakan press conference \\
dan press release dengan mengundang beberapa media.
\end{tabular}

Evaluation melakukan evaluasi yaitu dengan quesioner kepada tenant dan pengunjung Revo Town. Evalusi ini dijalankan setiap enam bulan sekali. Indikator keberhasilan evaluasi ini yaitu masyarakat aware dengan perubahan yang dilakukan oleh Revo Town serta adanya peningkatan jumlah pengunjung.

Sumber : diolah berdasarkan interview pada informan

Pelaksanaan rebranding Revo Town tidak lepas dari pemanfaatan media untuk memperkenalkan brand barunya tersebut. Media merupakan salah satu alat untuk menyampaikan pesan kepada publik. Beberapa media yang digunakan Revo Town dalam memperkenalkan rebranding Revo Town yaitu media cetak yang terdiri dari koran-koran lokal yang berada di Bekasi, bulletin, Brosur, Flyer, baliho dan billboard. Selain itu, Revo Town menggunakan media digital yang terdiri dari situs berita online, media sosial, serta website. Hal ini selaras dengan penelitian Laily Maknin Zubaedah yang menekankan penggunaan media internet dalam proses rebranding. 
Revo Town. Revo Town juga bekerjasama dengan Radio M2E untuk menyampaikan informasi kepada masyarakat. Pemilihan media yang digunakan oleh Revo Town diatas sudah tepat. Dalam menjalakan proses rebranding Bekasi Square menjadi Revo Town, perusahaan menginginkan masyarakat mempunyai kesadaran akan brand baru Revo Town tersebut. Namun, kenyataan yang muncul adalah manajemen Revo Town tidak memperoleh apa yang yang diinginkan secara maksimal karena adanya kendala yang ditemui dalam proses rebranding tersebut.

Divisi Marketing Communication Revo Town menemukan kendala dalam proses rebranding Bekasi Square menjadi Revo Town yaitu sulitnya membentuk kesadaran masyarakat dalam mengenal brand baru Revo Town. Masyarakat masih belum familiar dengan brand Revo Town. Kebanyakan dari masyarakat masih terpaku dengan brand lama yaitu Bekasi Square. Hal ini terjadi karena masyarakat sudah cukup lama mengenal brand Bekasi Square.

Solusi yang digunakan oleh Revo Town dalam mengatasi kendala tersebut yaitu dengan gencar melakukan promosi diberbagai media yang digunakan oleh Revo Town. Selain itu, Marketing Communication melakukan beberapa strategi agar masyarakat aware dengan brand baru Revo Town yaitu pertama dengan mengadakan event. Event merupakan salah satu strategi yang tepat untuk memperkenalkan brand Revo Town kepada masyarakat. Event marketing mempunyai kekuatan yang luar biasa untuk menciptkan brand awareness kepada konsumen sehingga dalam dirinya tumbuh fanatisme terhadap produk tertentu ( Ilhamdi, 2008:1). Kedua, dengan mengadakan program loyalitas konsumen. Program loyalitas konsumen ini merupakan salah satu strategi perusahaan untuk menjalin hubungan positif dengan konsumennya. Dalam program loyalitas konsumen tersebut, Marketing Communications Revo Town akan memberikan beberapa voucher serta merchandise kepada pengunjung dengan disertai syarat dan ketentuan yang telah ditentukan.

\section{SIMPULAN}

Media televisi pada dasarnya merupakan arena symbol atau tanda-tanda. Tanda sebagai sistem bahasa dalam teks televisi dapat dimaknai dengan menggunakan metode semiotika. Dengan pendekatan analisis semiotika Roland Barthes dan Teori Konstruksi Realitas Sosial Berger dan Luckmann terhadap perayaan imlek pada film animasi Upin dan Ipin dalam episode "Gong $\mathrm{Xi} \mathrm{Fa}$ Cai” di MNCTV, terlihat film ini menjelaskan perayaan imlek yang biasa dilakukan masyarakat etnis Tionghoa pada saat hari raya Imlek.

Berdasarkan hasil penelitian dan pembahasan pada bab sebelumnya, maka dapat diambil kesimpulan pertama, strategi Public Relations dalam rebranding Bekasi Square menjadi Revo Town yaitu melalui tahap repositioning, renaming, redesigning, dan relaunching. Tahap repositioning dilakukan dengan memperkuat brand Revo Town sebagai satu-satunya pusat perbelanjaan dengan tenant tekstile terlengkap dan terbesar di Bekasi. Repositioning Revo Town telah dijalankan dengan baik. Hal ini terlihat dengan banyaknya tenant tekstile yang bergabung di Revo Town. Tahap Renaming yang dilakukan dalam proses rebranding Revo Town yaitu dengan mengubah nama Bekasi Square menjadi Revo Town. Revo Town berasal dari kata Revo yang berarti revolution dan Town yang mempresentasikan sebagai a melting pot untuk teman dan keluarga. Tahap redesigning Revo Town dilakukan dengan mengubah logo Bekasi Square menjadi Revo Town yang lebih dominan menggunakan warna orange yang memberikan kesan hangat dan nyaman. Selain itu, mengganti tagline Revo Town menjadi simply a place for togetherness and family quality time. Proses relaunching Revo Town dijalankan dengan cara mengadakan press conference pada saat grand launching. Selain itu, divisi Marketing Communication membagikan press release kepada media pada saat kegiatan grand launching berlangsung.

Kedua, dalam proses rebranding Bekasi Square menjadi Revo Town, terdapat kendala yang dihadapi oleh Marketing Communication Revo Town. Kendala yang dihadapi adalah sulitnya membentuk kesadaran masyarakat akan perubahan yang dilakukan oleh Revo Town. Selain itu, masyarakat juga masih terpaku dengan nama Bekasi Square. Ketiga, solusi yang digunakan untuk 
menangani kendala diatas yaitu dengan gencar melakukan kegiatan promosi diberbagai media promosi yang digunakan, menyelenggarakan event dan mengadakan program loyalitas konsumen.

\section{DAFTAR PUSTAKA}

Allen H. Center and Scott M. Cutlip. 1982. Effective Public Relations. New Jersey: Prentince Hall International.

Dida, Susanne Dida \& Budiana, Heru Ryanto. "Corporate Rebranding of Gramedia Store (Corporare Rebranding di Gramedia Store). Jurnal Educational Technology (EDUTECH) Vol 15, No 3 (2016).

Goi, CL., Goi, MT., 2011. Review on Models and Reasons of Rebranding. International Conference on Social Science and Humanity, Vol.5, Singapore.

Herdiansyah, Haris. 2010. Metodologi Penelitian Kualitatif Untuk Ilmu-Ilmu Sosial. Jakarta: Salemba Humanika.

Ilhamdi, Sulaeman. 2008. Manajemen Pemasaran Event Sponsorship. Jakarta: Erlangga

Jefkins, Frank. 2003. Public Relations. Jakarta: Erlangga

Maknin Zubaedah, Laily. "Corporate Rebranding Tokobagus.com menjadi OLX.co.id”. Jurnal Ilmiah Teknik dan Manajemen Industri (JITMI) Vol 1, No 1 (2018).

Muzellec, Laurent dan Mary Lambkin. 2006. "Corporate Rebranding: Destroying, transferring or Creating Brand Equity?”. European Journal of Marketing. Emerald Group Publishing Limited 40,No. 7-8.

European Journal of Marketing. Emerald Group Publishing Limited 40, No. 7-8.

Paul, Temporal dan KC. Lee. 2002. Hi-Tech Hi-Touch Branding. Jakarta: Salemba Empat.

Prasetya Yoga Santoso, Rialdo Rezeky M. L. Toruan. "Strategi Marketing Public Relations dalam Rebranding HSBC Indonesia untuk membentuk Brand Awareness". Jurnal Pustaka Komunikasi Vol 1, No 1 (2018).

Priansa, Donni Juni. 2017. Komunikasi Pemasaran Terpadu. (Cetakan 1). Bandung: Pustaka Setia.

Ruslan, Rosady. (2014). Manajemen Public Relations dan Media Komunikasi Konsep dan Aplikasinya (Edisi Revisi). Jakarta: Raja Grafindo Persada. 